\title{
An Experimental Investigation of Victim Blaming in Sexual Assault: The Roles of Victim Sexual Orientation, Coercion Type, and Stereotypes About Bisexual Women
}

\author{
Christina Dyar \\ Brian A. Feinstein \\ RaeAnn E. Anderson \\ University of North Dakota, raeann.anderson@UND.edu
}

\section{How does access to this work benefit you? Let us know!}

Follow this and additional works at: https://commons.und.edu/psych-fac

Part of the Psychology Commons

\section{Recommended Citation}

Christina Dyar, Brian A. Feinstein, and RaeAnn E. Anderson. "An Experimental Investigation of Victim Blaming in Sexual Assault: The Roles of Victim Sexual Orientation, Coercion Type, and Stereotypes About Bisexual Women" (2019). Psychology Faculty Publications. 27.

https://commons.und.edu/psych-fac/27

This Article is brought to you for free and open access by the Department of Psychology at UND Scholarly Commons. It has been accepted for inclusion in Psychology Faculty Publications by an authorized administrator of UND Scholarly Commons. For more information, please contact und.commons@library.und.edu. 
An experimental investigation of victim blaming in sexual assault: The roles of victim sexual orientation, coercion type, and stereotypes about bisexual women

Christina Dyar, ${ }^{1 *}$ Brian A. Feinstein, ${ }^{1}$ and RaeAnn E. Anderson ${ }^{2}$

${ }^{1}$ Northwestern University, Institute for Sexual and Gender Minority Health and Wellbeing

${ }^{2}$ University of North Dakota, Department of Psychology

* Corresponding author: Christina Dyar, Northwestern University, Institute for Sexual and Gender Minority Health and Wellbeing; 625 N. Michigan Ave, Suite 1400, Chicago, IL, 60611; Phone: 312-503-3794; dyar.christina@northwestern.edu

\section{Citation}

Dyar, C., Feinstein, B.A., \& Anderson R.E. (in press). An experimental investigation of victim blaming in sexual assault: The roles of victim sexual orientation, coercion type, and stereotypes about bisexual women. Journal of Interpersonal Violence. doi: 10.1177/0886260519888209

Funding: This research was supported by grants from the Society for the Psychological Study of Social Issues and the Society for the Psychology of Women (Division 35) of the American Psychological Association. Brian Feinstein's time was supported by a grant from the National Institute on Drug Abuse (K08DA045575; PI: Feinstein). RaeAnn Anderson's time was supported by a grant from the National Institute on Alcohol Abuse and Alcoholism (K01AA026643; PI: Anderson). The content is solely the responsibility of the authors and does not necessarily represent the official views of the funding agencies.

This is a post-peer-review, pre-copyedit version of an article published in Journal of Interpersonal Violence. The final authenticated version is available online at: https://doi.org/10.1177/0886260519888209 


\begin{abstract}
Bisexual women are more likely to be sexually assaulted and to receive negative reactions to disclosures of sexual assault than heterosexual and lesbian women. However, few studies have examined the extent to which victim sexual orientation and related factors influence perceptions of sexual assault victims and perpetrators. To fill this gap, the current study used an experimental manipulation to examine the influence of victim sexual orientation and coercion type on perceptions of sexual assault victims and perpetrators. Participants $(N=826)$ were randomly assigned to read one of nine vignettes in which the sexual orientation of the female victim (bisexual, lesbian, heterosexual) and the type of coercion (verbal, physical, alcohol incapacitation) were varied. Then, participants were asked a series of questions about the victim and the perpetrator. Results indicated that bisexual and heterosexual female victims were both perceived as having wanted to have sex with the perpetrator more and as having "led the perpetrator on” more than lesbian victims. In contrast, victim sexual orientation was not associated with explicit ratings of victim or perpetrator responsibility or victim suffering. Bisexual female victims were also perceived as more promiscuous than both lesbian and heterosexual female victims. In turn, perceiving the victim as more promiscuous was associated with perceiving the victim as more responsible, having wanted to have sex with the perpetrator more, having "led the perpetrator on” more, and suffering less, and with perceiving the perpetrator as less responsible. In sum, our findings suggest that efforts to reduce sexual violence toward bisexual women should attend to negative attitudes toward bisexual women, especially the perception of bisexual women as promiscuous.
\end{abstract}

Key words: sexual assault, victim blame, sexual orientation, bisexual, lesbian 
Bisexual women are at increased risk for sexual assault compared to heterosexual and lesbian women (Conron, Mimiaga, \& Landers, 2010; Walters, Chen, \& Breiding, 2013). In a nationally representative US survey, as many as $46 \%$ of bisexual women reported having been sexually assaulted in their lifetime compared to $17 \%$ of heterosexual women and $13 \%$ of lesbian women (Walters et al., 2013). Bisexual women also receive more negative social reactions to disclosure of sexual assault than heterosexual women (Sigurvinsdottir \& Ullman, 2015), and these negative social reactions have a more detrimental impact on mental health for bisexual women than heterosexual and lesbian women (Sigurvinsdottir \& Ullman, 2015, 2016). Given these findings, it is not surprising that bisexual women who have experienced sexual assault report more depressive symptoms, PTSD symptoms, drug use, and alcohol use problems than heterosexual and lesbian women who have experienced sexual assault (Sigurvinsdottir \& Ullman, 2016). In light of these dramatic disparities, it is critical to identify factors that place bisexual women at risk for negative social reactions to disclosure of sexual assault, which can amplify the negative impact of sexual assault on mental health.

\section{Victim Blaming ${ }^{1}$ and Sexual Orientation}

In a recent nationally representative US survey, 18-31\% of people endorsed stereotypes that portrayed bisexual women as highly sexual (Dodge et al., 2016). These stereotypes depict bisexual women as sexually adventurous, promiscuous, and "performing” for the sexual attention of heterosexual men (Brewster \& Moradi, 2010; Friedman et al., 2014) and contribute to the sexual objectification of bisexual women (Friedman et al., 2014; Yost \& Thomas, 2012). The

\footnotetext{
${ }^{1}$ We use the term victim blaming to refer to the broad area of research focused on factors associated with perceptions of blame after sexual assault. The use of the term victim in this paper does imply that we endorse any of these stereotypes but rather, we appreciate the complexity of outcomes that may occur after a sexual assault regardless of the gender of the person who was harmed (Hockett \& Saucier, 2014). We use the phrase "victim blaming” to be consistent with prior research.
} 
high prevalence of these stereotypes is noteworthy given that the sexual objectification of women is associated with victim blaming among heterosexual men and women (e.g., Abrams, Viki, Masser, \& Bohner, 2003; Loughnan, Pina, Vasquez, \& Puvia, 2013) and with the perpetration of sexual assault among heterosexual men (Gervais, DiLillo, \& McChargue, 2014). As such, the hypersexualization of bisexual women may contribute to negative reactions to their disclosure of sexual assault, including an increased likelihood that others may blame them for what happened to them, which in turn may help to explain why bisexual women experience more negative outcomes post-assault. This hypersexualization may also help to explain why bisexual women are at elevated risk for sexual assault. In fact, recent qualitative research with bisexual women indicates that some bisexual women view these stereotypes as contributing to their being targeted for sexual assault (Flanders, Ross, Dobinson, \& Logie, 2017).

In spite of bisexual women’s greater risk for sexual assault and poorer recovery outcomes, only one existing study has examined differences in victim blaming for bisexual compared to lesbian and heterosexual female victims of sexual assault. Morrison and Pedersen (2018) randomly assigned participants to read one of three vignettes describing a physically forced sexual assault in which the sexual orientation of the female victim was varied (heterosexual, lesbian, bisexual, not listed). Contrary to hypotheses, they did not find differences in victim blame or perceived perpetrator responsibility when the victim was bisexual compared to when the victim was identified as lesbian or heterosexual or their sexual orientation was not specified. The authors noted that the results may have been affected by the demographic characteristics of their sample, which was predominately comprised of heterosexual female college students. Thus, further research is needed to determine whether the results generalize to more diverse samples (e.g., heterosexual men, gay and lesbian individuals, non-college students). 
A small number of studies have also examined blaming of lesbian compared to heterosexual female victims of sexual assault, but the results have been mixed. Specifically, two studies found that heterosexual women were blamed more than lesbian women for being sexually assaulted (Ford, Liwag-McLamb, \& Foley, 1998; Wakelin \& Long, 2003), and two others did not find significant differences in victim blame for heterosexual versus lesbian women who experienced sexual assault (Davies, Pollard, \& Archer, 2001; White \& Kurpius, 2002). Wakelin and Long (2003) proposed that heterosexual women may be blamed more than lesbian women because heterosexual women's sexual orientation is perceived as indicating the potential that they may have been sexually attracted to the perpetrator, which is consistent with several rape myths that place the blame on the victim (e.g., that the victim wanted to have sex with the perpetrator, "led the perpetrator on”, or “asked for it”; Edwards, Turchik, Dardis, Reynolds, \& Gidycz, 2011). In contrast, the authors proposed that lesbian women's sexual orientation may be perceived as less consistent with these rape myths resulting in less blame.

\section{Other Factors Influencing Victim Blaming}

Several other factors, including characteristics of the victim, the perpetrator, the sexual assault, and person assigning the blame (e.g., the study participant) have been linked to victim blaming. For example, research with samples of heterosexual individuals has found that male participants consistently blame sexual assault victims more and perpetrators less than female participants (Hockett, Smith, Klausing, \& Saucier, 2016). Situational factors also influence victim blaming, including the relationship of the perpetrator to the victim and the type of sexual assault. Victims who are assaulted by a stranger are blamed less than those who are assaulted by an acquaintance (for a review see Van Der Bruggen \& Grubb, 2014), and victims who had been drinking prior to the sexual assault are blamed more than those who had not been drinking (for a 
review see Grubb \& Turner, 2012). Additionally, victims are blamed less for sexual assaults involving physical force than those involving alcohol intoxication, with victim blaming being highest for verbally coerced sexual assault (e.g., Russell, Oswald, \& Kraus, 2011).

\section{Current Study}

This study aimed to determine whether bisexual women who experience sexual assault are viewed more negatively compared to heterosexual and lesbian women who experience sexual assault and if this is consistent across three types of coercion used in the assault (verbal, alcohol incapacitated, physical). We also aimed to examine whether stereotypes that portray bisexual women as highly sexual contribute to negative perceptions of bisexual women who have experienced sexual assault. Given that most victims are sexually assaulted by acquaintances and the high prevalence of alcohol incapacitated and verbally coerced sexual assaults (Black et al., 2011), we focused on sexual assaults by acquaintances and varied the type of coercion. Building on existing experimental vignette studies, we randomly assigned participants to read one of a series of vignettes describing a woman being sexually assaulted by a man. In these vignettes, the sexual identity of the victim of the sexual assault (i.e., heterosexual, lesbian, bisexual) and the type of coercion used (i.e., verbal, alcohol incapacitation, physical force) were varied.

We hypothesized that bisexual women who experienced sexual assault would be viewed more negatively, including 1) being explicitly rated as more responsible for being sexually assaulted, 2) being perceived as having wanted to have sex with the perpetrator more, and 3) being perceived as having “led the perpetrator on” more compared to heterosexual and lesbian women. We also expected that perpetrators of sexual assaults against bisexual women would be perceived as less responsible than perpetrators of assaults against lesbian and heterosexual women, and that bisexual women would be seen as suffering less as a result of being sexually 
assaulted than heterosexual and lesbian women. Second, we explored whether differences in perceptions of the victim and perpetrator were dependent on the tactic of coercion (i.e., verbal, alcohol, physical). Given a lack of research, we did not make a priori hypotheses regarding the direction of this potential moderation. Third, we expected that bisexual victims would be perceived as more promiscuous than lesbian and heterosexual victims, and that this would help explain differences in perceptions of the victim and perpetrator when the sexual assault involved a bisexual woman relative to a lesbian or heterosexual woman. Fourth, we hypothesized that having more negative views of bisexual women in general would be associated with perceiving the victim as more responsible, as having wanted to have sex with the perpetrator more or "led the perpetrator on” more, as more promiscuous, and as suffering less when the victim was bisexual as well as with perceiving the perpetrator of assaults against bisexual women as less responsible. We hypothesized a similar pattern of associations between negative perceptions of lesbians in general and perceptions of the victim and perpetrator when the victim was a lesbian.

\section{Methods}

\section{Procedure}

All participants were recruited through Amazon’s Mechanical Turk (MTurk) and were paid a nominal fee for their participation. MTurk is a crowdsourcing website where individuals can complete tasks and participate in research studies in exchange for payment. Studies of MTurk participation and demographics indicate that MTurk participants are more diverse and may be more attentive than subject pool participants (Chandler \& Shapiro, 2016; Hauser \& Schwarz, 2016). Participants were required to be at least 18 years of age, live in the United States, be able to read English, be cisgender men or women, and self-identify as heterosexual, lesbian, or gay. After consenting, participants were directed to a secure website, Qualtrics, to 
complete a survey entitled "First Impressions," which sought to "learn about how people form impressions about people and situations with limited information.”

We used a between-subjects design in which each participant was randomly assigned to read one of nine vignettes in which the sexual orientation of the female victim (heterosexual, lesbian, or bisexual) and the type of coercion use (verbal, alcohol incapacitation, or physical force) were varied (see Appendix for vignette text). These vignettes were adapted from those used in three other studies of victim blaming in sexual assault (Abrams et al., 2003; Grubb \& Harrower, 2008; Loughnan et al., 2013). The main adaptations included: (1) changing the sexual orientation of the female character across conditions; (2) changing the type of coercion used across conditions (as in Grubb \& Harrower, 2008); and (3) making minor adaptations to the storyline of the vignettes in order to make them plausible regardless of the female character's sexual orientation (e.g., instead of having the female character invite the male character back to her apartment after a party, having the assault occurs at an acquaintance's party after all of the other guests had left). A minimum of 20 heterosexual men, 20 heterosexual women, 20 lesbian women, and 20 gay men completed each of the nine conditions. Due to random assignment, some cells were overfilled, particularly for heterosexual male and female participants (maximum cell size $=36$ ). After reading the vignette, participants were asked questions about the scenario, the perpetrator, and the victim, and were then asked about their perceptions of lesbian and bisexual women more broadly and their own experiences with sexual assault.

\section{Participants}

A total of 947 individuals completed the study. Of those participants, 121 (12.8\%) missed one or both attention checks embedded in the measures, and their data were excluded from the analytic sample. Demographic information for the analytic sample $(N=826)$ is presented in 
Table 1. The sample was predominately European American (75.4\%) and ranged in age from 18$78(M=38.6$ years, $S D=13.1)$. Most participants had at least some college education $(87.9 \%)$.

\section{Measures}

\section{Perceptions of the victim and perpetrator}

Perceived victim and perpetrator responsibility were measured using an adapted version of the 7-item measure developed by Abrams and colleagues (2003). The original measure included five items that assessed perceived victim responsibility (e.g., How much do you think Laura should blame herself for what happened?”), one item that assessed perceived perpetrator responsibility (“How much control do you think Mike had over the situation?”), and one item that combined these two dimensions ("Whose fault do you think it is that things turned out the way they did?” on a scale of 1 [Mike] to 7 [Laura]). To adapt this measure to assess victim and perpetrator responsibility as separate dimensions, we split the original item "Whose fault do you think it is that things turned out the way they did?" into two items: "How much do you think it is Laura’s [Mike's] fault that things turned out the way they did?” with response scales of 1 (not at all) to 7 (completely). We also created another item that mirrored the original item "How much sympathy do you feel for Laura?” asking about sympathy for the perpetrator. The adapted 9-item scale included 6 items that assessed perceived victim responsibility $(\alpha=.84)$ and 3 items that assessed perceived perpetrator responsibility $(\alpha=.75)$.

Endorsement of stereotypes about victims of sexual assault were assessed using two subscales of a measure developed by Abrams et al. (2003). Endorsement of the belief that the victim really wanted to have sex with the perpetrator was assessed using 4 items (e.g., "Laura really wanted to have sex with Mike"; $\alpha=.93$ ) and endorsement of the belief that the victim "led the perpetrator on" was via 5 items (e.g., "Laura got what she deserved for teasing Mike"; $\alpha=$ 
.86). Responses were provided on a scale of 1 (completely disagree) to 7 (completely agree).

Perceived promiscuity of the victim was assessed by asking participants, "How well do each of the following describe Laura?” Participants indicated whether the words "promiscuous," “sexually adventurous," and "sexually experienced” described Laura on a scale of 1 (not at all) to 7 (very well). These items demonstrated internal consistency $(\alpha=.82)$. This measure is similar to others used to assess perceptions of victims of sexual assault (e.g., Abrams et al., 2003).

Victim suffering was assessed using a 3-item measure developed by Loughnan and colleagues (2013). Participants were asked to indicate "How much did Laura suffer as a result of this encounter with Mike?” on a scale of 1 (not at all) to 6 (a great deal), "How long will it take Laura to recover from the encounter and go about her life as before?” (response options ranged from 0-10 years in 2-year increments), and to "indicate the amount of counseling that should be made available to Laura” (response options ranged from 0-10 weeks in 2-week increments). We changed references to "the crime" in the original items to "the encounter" to reduce demand effects. Items demonstrated adequate internal consistency $(\alpha=.74)$.

Attitudes toward lesbian and bisexual women were assessed using three measures. The hostility subscale of the Attitudes Regarding Bisexuality Scale (ARBS; Mohr \& Rochlen, 1999) was used to assess hostility toward bisexual women and perceptions of bisexual women as immoral. This measure includes 6 items (e.g., "Bisexuality in women is immoral;” $\alpha=.95$ ) assessed on a scale of 1 (strongly disagree) to 5 (strongly agree). Endorsement of stereotypes that bisexual women are uncertain about their sexual orientation and sexually promiscuous were assessed using the Bisexualities Indiana Attitudes Scale (BIAS; Friedman et al., 2014). This measure includes 26 items (e.g., “Bisexual women can’t make up their mind about their sexuality” and "Bisexual women would have sex with just about anyone;" $\alpha=.93$ ) on a scale of 
1 (strongly agree) to 5 (strongly disagree). Attitudes toward lesbian women were assessed using the 12-item Modern Homonegativity Scale (e.g., "Lesbians should stop complaining about the way they are treated in society, and simply get on with their lives;” $\alpha=.78$ ), which uses the response options 1 (strongly disagree) to 5 (strongly agree) (M. A. Morrison \& Morrison, 2003). The Modern Homonegativity Scale (MHS) was not administered to lesbian and gay participants; therefore, analyses including this scale were conducted with only heterosexual participants.

Participants' experiences of sexual assault were assessed using brief versions of the Post Refusal Response Scale (BPRS) for victimization (Struckman-Johnson, StruckmanJohnson, \& Anderson, 2003) and the Sexual Strategies Scale (SSS) for perpetration (Strang, Peterson, Hill, \& Heiman, 2013). In the original version of the scales, 19 items covering a wide range of tactics are assessed for victimization and then separately repeated for perpetration. In this study we selected five items representing three distinct types of tactics: verbal, alcohol, and physical force. We chose items that would represent the most common forms of sexual assault and that would correspond to the forms of sexual assault portrayed in the vignettes.

Victimization. In the brief PRS, we asked participants to indicate how many times various coercive tactics have been used to "have sexual contact (kissed, fondled, genital touching, oral sex, anal sex, or intercourse) with you after you have indicated 'no' to their sexual advance.” The five items assess verbal coercion ("told you a lie of some kind [i.e., told you how much they liked/loved you;" "tried to talk you into it by repeatedly asking”), physical force (or the threat of force; i.e., "used physical force [twisting their arm, holding them down, etc.];” “threatening to use physical force”), and drug/alcohol incapacitation (“taken advantage of you when you were too intoxicated to give consent or stop what was happening”) on a five point response scale of 0 to $10+$ times. Responses across items were dichotomized to reflect whether 
participants had experienced a sexual assault $(n=500)$ or had not $(n=326)$.

Perpetration. In the brief SSS we asked participants to indicate how many times they had used various strategies "to convince someone to have sex (oral, anal or vaginal intercourse) or sexual contact (kissing, making out, touching private parts or genitals) with you when they did not want to.” Items mirroring (5) those used in the brief PRS were used to assess the same three types of coercion and use the same 0 to $10+$ times response scale. Responses across items were dichotomous to reflect whether participants had perpetrated a sexual assault $(n=203)$ or had not perpetrated a sexual assault $(n=623) .^{2}$

\section{Results}

Less than $0.1 \%$ of data were missing and this was handled using pairwise deletion. All analyses were conducted in SPSS and the Process macro was used to test indirect effects (Hayes, 2016). Correlations and descriptive statistics are presented in Table 2. As participant age, gender, sexual orientation, and experiences of sexual assault victimization and perpetration were associated with perceptions of the victim and perpetrator, they were controlled for in all analyses.

\section{Condition Effects}

Victim sexual orientation. To test hypotheses that bisexual victims of sexual assault would be perceived more negatively than lesbian and heterosexual victims, we examined the main effects of victim sexual orientation on perceptions of the victim and perpetrator using analyses of covariance (ANCOVAs; see Tables 3-4 for ANCOVAs and marginal means). In addition to the participant characteristics described above, condition coercion type was

\footnotetext{
${ }^{2}$ We did not compute Cronbach's alpha for the two measures of participants' experiences of sexual assault as Cronbach's alpha is a measure of reliability recommended for latent constructs wherein each items represents a facet of the underlying latent construct (Sijtsma, 2009). The PRS and SSS are measures of behavioral experiences rather than a latent construct and experiences of perpetration or victimization are not necessarily expected to be related to one another (Diamantopoulos, Riefler, \& Roth, 2008; Koss et al., 2007).
} 
controlled for. Victim sexual orientation was significantly associated with three outcomes:

perceptions that the victim wanted to have sex with the perpetrator, perceptions that the victim "led the perpetrator on,” and perceived promiscuity of the victim. Follow-up least significant difference (LSD) tests indicated that heterosexual and bisexual women were perceived to have wanted to have sex with the perpetrator and to have "led the perpetrator on" more so than lesbian victims. Contrary to hypotheses, heterosexual and bisexual victims did not differ on these variables and there were no differences by sexual orientation on perceived responsibility of the perpetrator or victim or on victim suffering. Consistent with hypotheses, bisexual victims of sexual assault were perceived to be more promiscuous than lesbian or heterosexual victims.

Coercion type. Coercion type was a consistent predictor of perceptions of the victim and perpetrator, see Tables 3-4. Follow-up LSD tests indicated that victims of sexual assaults that involved physical force were viewed as less responsible for being sexually assaulted, less likely to be viewed as wanting to have sex with the perpetrator or having "led the perpetrator on," and as suffering more than victims of alcohol incapacitated sexual assaults. Perpetrators of assaults involving physical force were viewed as more responsible than perpetrators of alcohol incapacitated assaults. Perceptions of victims of sexual assaults involving verbal coercion generally fell between physical force and alcohol incapacitation but did not always differ significantly from either group.

Participant characteristics. While our main focus was on the condition effects, several covariates were significantly associated with perceptions of the perpetrator and victim, see Table 3-4. Cisgender women, lesbian/gay individuals, and participants who had not perpetrated sexual assaults viewed victims of sexual assault as less responsible, having wanted to have sex with the perpetrator less or "led the perpetrator on” less, suffering more, being less promiscuous, and 
viewed perpetrators as more responsible than cisgender men, heterosexual individuals, and participants who had perpetrated sexual assaults. Participants who had been sexually assaulted viewed victims of sexual assault as less likely to have wanted to have sex with the perpetrator compared to participants who had not but they did not differ on other variables.

Victim sexual orientation by coercion type. Following examination of the main effects of the two condition variables in Model 1, we added the interaction between victim sexual orientation and coercion type to the main effects models (see Model 2 in Table 3). None of the interactions were significant, indicating that the effects of victim sexual orientation on perceptions of the victim and perpetrator did not differ by coercion type.

\section{Indirect Effects}

Next, we tested the hypothesis that bisexual victims would be perceived as more promiscuous than lesbian and heterosexual victims, and that this would be a mechanism through which victim sexual orientation was associated with perceptions of the victim and perpetrator. Although we did not detect many differences in perceptions of the victim and perpetrator when the victim was bisexual versus lesbian/heterosexual, statisticians argue that a significant direct effect is not a necessary condition for testing for an indirect effect. This is because an indirect effect can be significant when a direct effect is not (Kenny \& Judd, 2014; Rucker, Preacher, Tormala, \& Petty, 2011). Indirect effects analyses using the bootstrap approach with 5,000 resamples (see Table 5) indicated that bisexual victims were perceived to be more promiscuous than lesbian and heterosexual victims, and that being perceived as more promiscuous was associated with perceiving the victim as more responsible, as having wanted to have sex with the perpetrator more, as having “led the perpetrator on” more, and as suffering less, as well as perceiving the perpetrator as less responsible. All of these indirect effects were significant. This 
indicates that although we did not detect significant differences between bisexual and lesbian/heterosexual women on many of these variables, bisexual victims were perceived as more promiscuous, which in turn was associated with more negative perceptions of the victim. Associations between Attitudes Toward and Perceptions of Bisexual and Lesbian Victims

Next, we examined associations between attitudes toward bisexual women in general and perceptions of sexual assaults in which the victim was bisexual (see Table 6). Results indicated that more negative views of bisexual women (indicated by lower scores on the ARBS and BIAS) were associated with perceiving bisexual victims of sexual assault as more responsible, as having wanted to have sex with the perpetrator more, as having "led the perpetrator on" more, as more promiscuous, and as suffering less, as well as with perceiving the perpetrator of an assault of a bisexual woman as less responsible. The same pattern of findings was present between attitudes toward lesbians in general and more negative views of lesbian victims of sexual assaults.

\section{Discussion}

Bisexual women are more likely to be sexually assaulted than heterosexual and lesbian women (Conron et al., 2010; Walters et al., 2013) and they receive more negative reactions when they disclosure experiences of sexual assault (Sigurvinsdottir \& Ullman, 2015, 2016). While several studies have examined differences in the extent to which lesbian versus heterosexual women are blamed for being sexually assaulted, only one has compared perceptions of bisexual, lesbian, and heterosexual women in spite of bisexual women's greater risk for sexual assault (Morrison \& Pedersen, 2018). Further, the sample in that study was largely comprised of heterosexual female college students, a demographic that tends to hold less negative perceptions of victims of sexual assault (Van Der Bruggen \& Grubb, 2014) and more positive attitudes toward lesbians and bisexual women than other demographics (Horn, 2012; Lytle, Dyar, Levy, \& 
London, 2017). The goal of the current study was to extend this work by examining the extent to which perceptions of victims and perpetrators of sexual assault differed depending on the sexual orientation of the victim and the type of coercion used in the sexual assault in a sample that included gay/lesbian and heterosexual men and women. Further, we also examined whether stereotypes that portray bisexual women as highly sexual contribute to victim blaming of bisexual women who have experienced sexual assault.

Previous research on sexual orientation and victim blaming has led to mixed findings, with two studies finding that heterosexual women were blamed more than lesbian women (Ford et al., 1998; Wakelin \& Long, 2003) while two others did not replicate this effect (Davies et al., 2001; White \& Kurpius, 2002). In the current study, we found that, compared to lesbian victims, both bisexual and heterosexual female victims were perceived as wanting to have sex with the perpetrator and leading the perpetrator on more than lesbian victims. In contrast, victim sexual orientation was not associated with perceptions of victim or perpetrator responsibility or victim suffering. Our findings are consistent with the notion that heterosexual women may be blamed more than lesbian women when they are sexually assaulted by men because their sexual orientation includes attraction to men (Wakelin \& Long, 2003). Further, our findings extend this notion to bisexual women, whose sexual orientation also includes attraction to men. Together, these findings highlight the importance of perceived attraction to men as a potential contributor to whether or not someone is blamed for being sexually assaulted by a man.

We also found that bisexual female victims were perceived as more promiscuous than both lesbian and heterosexual female victims. In turn, being perceived as more promiscuous was associated with perceiving the victim as more responsible, having wanted to have sex with the perpetrator more, having "led the perpetrator on” more, and as suffering less, as well as 
perceiving the perpetrator as less responsible. Although our study utilized fictional vignettes, our findings suggest that perceptions of bisexual women as promiscuous may contribute to their increased risk of receiving negative reactions to disclosures of sexual assault (Sigurvinsdottir \& Ullman, 2015, 2016) and potentially their increased risk of being sexually assaulted (Conron et al., 2010; Walters et al., 2013). Of note, the same pattern of findings was present between attitudes toward lesbian women and more negative views of lesbian victims of sexual assault compared to heterosexual female victims of sexual assault. Together, these findings suggest that negative attitudes toward sexual minority women contribute to victim blaming in sexual assault. Third, we found significant differences in perceptions of victim and perpetrator blame based on the type of coercion used in the sexual assault. Victims of sexual assaults that involved physical force were viewed as less responsible for being sexually assaulted, less likely to be viewed as wanting to have sex with the perpetrator or having "led the perpetrator on," and as suffering more than victims of alcohol incapacitated sexual assaults compared to victims of sexual assaults involving verbal coercion or alcohol incapacitation. This is consistent with the existing literature, which finds that victims are blamed less as the degree of physical force used by the perpetrator increases (Hockett et al., 2016; Van Der Bruggen \& Grubb, 2014) and that victims of verbally coerced sexual assault are blamed more than victims of sexual assaults involving physical force (Katz, Moore, \& Tkachuk, 2007). Perceptions of victims of sexual assaults involving verbal coercion generally fell between physical force and alcohol incapacitation, but they did not always differ significantly from either group. Direct comparisons of the perceptions of victims of sexual assault involving verbal coercion versus alcohol incapacitation are infrequent. However, consistent with our findings, research tends to indicate that when other contextual variables are held constant, victims who consumed alcohol prior to being sexually assaulted tend to be blamed 
more than those who did not and perpetrators who consumed alcohol prior to committing a sexual assault are blamed less (Grubb \& Turner, 2012; Hockett et al., 2016).

Finally, several participant characteristics were significantly associated with perceptions of the victim and the perpetrator. Consistent with previous research (for a review, see van der Bruggen \& Grubb, 2014), we found that cisgender women viewed victims of sexual assault as less responsible, having wanted to have sex with the perpetrator less, having "led the perpetrator on” less, suffering more, and being less promiscuous, and viewed the perpetrator as more responsible than cisgender men. There has been less research on the influence of participant sexual orientation on perceptions of victims and perpetrators, but our findings were also consistent with the limited research in this area (Davies \& Hudson, 2011; Davies \& McCartney, 2003), demonstrating that gay and lesbian people tend to place less blame on victims and more blame on perpetrators compared to heterosexual people. Of note, these previous studies focused on perceptions of male victims, and our findings suggest that this pattern extends to female victims as well. Finally, we found that participant history of sexual assault victimization and perpetration also influenced their perceptions. Specifically, participants who had been sexually assaulted viewed victims as less likely to have wanted to have sex with the perpetrator compared to those who had not been sexually assault, and participants who had not perpetrated sexual assaults perceived the victims as less responsible and the perpetrators as more responsible compared to those who had perpetrated sexual assaults. This is consistent with prior research showing that people who have experienced rape are more empathic to survivors and that people who have perpetration histories tend to be more empathic to perpetrators (e.g., Osman, 2011).

\section{Implications for Policy and Practice}

These findings highlight how stereotypes about bisexual women and sexual assault are 
harmful. First, these findings highlight a potential mechanism of inhibited recovery after sexual assault for bisexual women. Bisexual women who disclose their sexual assaults while seeking support are more likely to experience victim blaming and other negative reactions predicated upon how responsible they are perceived to be. This suggests that psychoeducation interventions that train community members in the provision of positive social support may be helpful in reducing the impact of sexual assault, especially for those with stereotyped identities such as sexual minority women. Further, incorporating transdiagnostic minority stress processes into therapies for posttraumatic stress disorder, depression, and other common post-sexual assault diagnoses may improve outcomes for sexual minorities (Burton, Wang, \& Pachankis, 2017).

These findings suggest that the perceived promiscuity and greater blameworthiness of bisexual women may be a mechanism of sexual perpetration against bisexual women. This is consistent with research on physical violence against sexual minorities, which indicates that stereotypes about sexual minorities are used to justify violence against them (Parrott \& Lisco, 2015). Interventions and policies that hold perpetrators responsible for sexual assaults are needed and would likely decrease the public health burden shouldered by the LGBTQ community.

\section{Limitations}

The current findings should be considered in light of several study limitations. Although this was likely the first study to include sexual minority men and women, we only included cisgender individuals who identified as lesbian/gay or heterosexual. As such, findings cannot be generalized to people of other genders and sexual orientations. Second, given that we used a between-subjects design, different participants read and answered questions about each vignette. A within-person design would have allowed participants to serve as their own controls, allowing for the examination of how people view bisexual victims relative to heterosexual victims while 
controlling for any individual level characteristics of the participant. Third, it is possible that giving the characters in the vignette specific and relatively common names may have biased some respondents who knew people with these names.

\section{Conclusions}

Given that bisexual women are at increased risk for sexual assault compared to both heterosexual and lesbian women (Conron et al., 2010; Walters et al., 2013), there is a critical need for tailored prevention and intervention efforts focused on this population. Our findings indicate the centrality of negative stereotypes about sexual minorities in facilitating victim blame. Based on our findings, efforts to reduce sexual violence toward bisexual women should attend to negative attitudes toward bisexual women, especially perceptions that bisexual women are promiscuous. Negative attitudes toward lesbian women were also associated with perceiving lesbian victims as more responsible for being sexually assaulted, suggesting a need to reduce negative attitudes toward both bisexual and lesbian women in order to reduce sexual violence toward these populations. Interventions to increase social support in the community for those who experience sexual assault, help sexual minorities cope with the burden of being stereotyped, and increase perceived responsibility for perpetration are recommended. Given that some participants (cisgender men, heterosexual individuals, and those who had perpetrated sexual assaults) were more likely than others to blame victims for being sexually assaulted, prevention efforts should prioritize these populations. Additionally, efforts should be made to reduce the perceived responsibility of victims of sexual assaults involving verbal coercion or alcohol incapacitation, as results indicate that they are blamed more than victims of sexual assaults involving physical force. In sum, the current findings highlight the critical need to consider negative attitudes toward bisexual and lesbian women in the field of sexual assault prevention. 


\section{References}

Abrams, D., Viki, G. T., Masser, B., \& Bohner, G. (2003). Perceptions of stranger and acquaintance rape: The role of benevolent and hostile sexism in victim blame and rape proclivity. Journal of Personality and Social Psychology, 84, 111-125. doi:10.1037/00223514.84.1.111

Black, M. C., Basile, K. C., Breiding, M. J., Smith, S. G., Walters, M. L., Merrick, M. T., .. . Stevens, M. R. (2011). The National Intimate Partner and Sexual Violence Survey (NISVS): 2010 Summary Report. . Atlanta, GA: National Center for Injury Prevention and Control, Centers for Disease Control and Prevention.

Brewster, M. E., \& Moradi, B. (2010). Perceived experiences of anti-bisexual prejudice: Instrument development and evaluation. Journal of Counseling Psychology, 57, 451-468. doi:10.1037/a0021116

Burton, C. L., Wang, K., \& Pachankis, J. E. (2017). Psychotherapy for the spectrum of sexual minority stress: Application and technique of the ESTEEM treatment model. Cognitive and Behavioral Practice.

Chandler, J., \& Shapiro, D. (2016). Conducting clinical research using crowdsourced convenience samples. Annual Review of Clinical Psychology, 12.

Conron, K. J., Mimiaga, M. J., \& Landers, S. J. (2010). A Population-Based Study of Sexual Orientation Identity and Gender Differences in Adult Health. American Journal of Public Health, 100, 1953-1960. doi:10.2105/AJPH.2009.174169

Davies, M., \& Hudson, J. (2011). Judgments toward male and transgendered victims in a depicted stranger rape. Journal of Homosexuality, 58, 237-247.

Davies, M., \& McCartney, S. (2003). Effects of gender and sexuality on judgements of victim 
blame and rape myth acceptance in a depicted male rape. Journal of Community \& Applied Social Psychology, 13, 391-398.

Davies, M., Pollard, P., \& Archer, J. (2001). The influence of victim gender and sexual orientation on judgments of the victim in a depicted stranger rape. Violence and Victims, 16, 607.

Diamantopoulos, A., Riefler, P., \& Roth, K. P. (2008). Advancing formative measurement models. Journal of business research, 61, 1203-1218.

Dodge, B., Herbenick, D., Friedman, M. R., Schick, V., Fu, T. J., Bostwick, W., . . Sandfort, T. G. (2016). Attitudes toward bisexual men and women among a nationally representative probability sample of adults in the United States. PloS One, 11, e0164430. doi:10.1371/journal.pone.0164430

Edwards, K. M., Turchik, J. A., Dardis, C. M., Reynolds, N., \& Gidycz, C. A. (2011). Rape myths: History, individual and institutional-level presence, and implications for change. Sex Roles, 65, 761-773.

Flanders, C. E., Ross, L. E., Dobinson, C., \& Logie, C. H. (2017). Sexual health among young bisexual women: A qualitative, community-based study. Psychology \& Sexuality, 8, 104117.

Ford, T. M., Liwag-McLamb, M. G., \& Foley, L. A. (1998). Perceptions of rape based on sex and sexual orientation of victim. Journal of Social Behavior and Personality, 13, 253.

Friedman, M. R., Dodge, B., Schick, V., Herbenick, D., Hubach, R., Bowling, J., . . Reece, M. (2014). From bias to bisexual health dispartities: Attitudes toward bisexual men and women in the United States. LGBT health, 1, 309-318.

Gervais, S. J., DiLillo, D., \& McChargue, D. (2014). Understanding the link between men’s 
alcohol use and sexual violence perpetration: The mediating role of sexual objectification. Psychology of Violence, 4, 156.

Grubb, A., \& Harrower, J. (2008). Attribution of blame in cases of rape: An analysis of participant gender, type of rape and perceived similarity to the victim. Aggression and Violent Behavior, 13, 396-405.

Grubb, A., \& Turner, E. (2012). Attribution of blame in rape cases: A review of the impact of rape myth acceptance, gender role conformity and substance use on victim blaming. Aggression and Violent Behavior, 17, 443-452.

Hauser, D. J., \& Schwarz, N. (2016). Attentive Turkers: MTurk participants perform better on online attention checks than do subject pool participants. Behavior Research Methods, 48, 400-407.

Hayes, A. F. (2016). The PROCESS macro for SPSS and SAS. URL: http://www. processmacro. org/index. html (visited on 12/07/2017).

Hockett, J. M., Smith, S. J., Klausing, C. D., \& Saucier, D. A. (2016). Rape myth consistency and gender differences in perceiving rape victims: A meta-analysis. Violence Against Women, 22, 139-167.

Horn, S. S. (2012). Attitudes about Sexual Orientation. In C. J. Patterson \& A. R. D'Augelli (Eds.), Handbook of Psychology and Sexual Orientation: Oxford Scholarship Online.

Katz, J., Moore, J. A., \& Tkachuk, S. (2007). Verbal sexual coercion and perceived victim responsibility: Mediating effects of perceived control. Sex Roles, 57, 235-247.

Koss, M. P., Abbey, A., Campbell, R., Cook, S., Norris, J., Testa, M., . . White, J. (2007). Revising the SES: A collaborative process to improve assessment of sexual aggression and victimization. Psychology of Women Quarterly, 31, 357-370. 
Loughnan, S., Pina, A., Vasquez, E. A., \& Puvia, E. (2013). Sexual Objectification Increases Rape Victim Blame and Decreases Perceived Suffering. Psychology of Women Quarterly, 37, 455-461. doi:10.1177/0361684313485718

Lytle, A., Dyar, C., Levy, S. R., \& London, B. (2017). Contact with Bisexual Individuals Reduces Binegativity among Heterosexuals and Lesbian Women and Gay Men. European Journal of Social Psychology, 47, 580-599. doi:10.1002/ejsp.2241

Mohr, J. J., \& Rochlen, A. B. (1999). Measuring attitudes regarding bisexuality in lesbian, gay male, and heterosexual populations. Journal of Counseling Psychology, 46, 353-369.

Morrison, K. E., \& Pedersen, C. L. (2018). The influence of sexual orientation on attributions of blame toward victims of sexual assault. Journal of Homosexuality, 1-17.

Morrison, M. A., \& Morrison, T. G. (2003). Development and validation of a scale measuring modern prejudice toward gay men and lesbian women. J of Homosexuality, 43, 15-37.

Osman, S. L. (2011). Predicting rape empathy based on victim, perpetrator, and participant gender, and history of sexual aggression. Sex Roles, 64, 506-515.

Parrott, D. J., \& Lisco, C. G. (2015). Effects of alcohol and sexual prejudice on aggression toward sexual minorities. Psychology of Violence, 5, 256.

Russell, B. L., Oswald, D. L., \& Kraus, S. M. (2011). Evaluations of sexual assault: Perceptions of guilt and legal elements for male and female aggressions using various coercive strategies. Violence and Victims, 26.

Sigurvinsdottir, R., \& Ullman, S. E. (2015). The Role of Sexual Orientation in the Victimization and Recovery of Sexual Assault Survivors. Violence and Victims, 30, 636-648.

Sigurvinsdottir, R., \& Ullman, S. E. (2016). Sexual Orientation, Race, and Trauma as Predictors of Sexual Assault Recovery. J Fam Violence, 31, 913-921. 
Sijtsma, K. (2009). On the use, the misuse, and the very limited usefulness of Cronbach's alpha. Psychometrika, 74, 107.

Strang, E., Peterson, Z. D., Hill, Y. N., \& Heiman, J. R. (2013). Discrepant responding across self-report measures of men's coercive and aggressive sexual strategies. Journal of Sex Research, 50, 458-469.

Struckman-Johnson, C., Struckman-Johnson, D., \& Anderson, P. B. (2003). Tactics of sexual coercion: When men and women won't take no for an answer. Journal of Sex Research, 40, 76-86.

Van Der Bruggen, M., \& Grubb, A. (2014). A review of the literature relating to rape victim blaming: An analysis of the impact of observer and victim characteristics on attribution of blame in rape cases. Aggression and Violent Behavior, 19, 523-531.

Wakelin, A., \& Long, K. M. (2003). Effects of victim gender and sexuality on attributions of blame to rape victims. Sex Roles, 49, 477-487.

Walters, M. L., Chen, J., \& Breiding, M. J. (2013). The National Intimate Partner and Sexual Violence Survey (NISVS): 2010 Findings on Victimization by Sexual Orientation. http://www.cdc.gov/violenceprevention/nisvs/2010_soreport.html

White, B. H., \& Kurpius, S. E. R. (2002). Effects of victim sex and sexual orientation on perceptions of rape. Sex Roles, 46, 191-200.

Yost, M. R., \& Thomas, G. D. (2012). Gender and binegativity: men's and women's attitudes toward male and female bisexuals. Archives of Sexual Behavior, 41, 691-702. 


\section{Table 1}

Sample Demographics $(N=826)$

\begin{tabular}{lcc}
\hline Participant Demographics & $n$ & $\%$ \\
\hline Gender by Sexual Orientation & & \\
Heterosexual Men & 227 & $27.5 \%$ \\
Heterosexual Women & 260 & $31.5 \%$ \\
Lesbian Women & 173 & $20.9 \%$ \\
Gay Men & 166 & $20.1 \%$ \\
Race/Ethnicity & & \\
European American/White & 623 & $75.4 \%$ \\
African American/Black & 71 & $8.6 \%$ \\
Latino/Hispanic & 53 & $6.4 \%$ \\
Asian & 52 & $6.3 \%$ \\
Other race/ethnicity & 27 & $3.3 \%$ \\
Education & & \\
High school & 100 & $12.1 \%$ \\
Some college & 195 & $23.6 \%$ \\
Associate's degree & 119 & $14.4 \%$ \\
Bachelor's degree & 294 & $35.6 \%$ \\
Graduate degree & 118 & $14.3 \%$ \\
& & \\
Age (M, SD) & $38.6(12.9)$ \\
\hline
\end{tabular}


Table 2

Correlations, Means, and Standard Deviations

\begin{tabular}{|c|c|c|c|c|c|c|c|c|c|c|c|c|c|}
\hline & 1 & 2 & 3 & 4 & 5 & 6 & 7 & 8 & 9 & 10 & 11 & 12 & 13 \\
\hline 1. Participant Age & - & & & & & & & & & & & & \\
\hline 2. Participant Gender & .001 & - & & & & & & & & & & & \\
\hline 3. Participant Sexual Orientation & .06 & -.02 & - & & & & & & & & & & \\
\hline 4. Participant SA Victim & .06 & $.20 * *$ & $.14^{* *}$ & & & & & & & & & & \\
\hline 5. Participant SA Perpetrator & .01 & $-.22 * *$ & .07 & $.26^{* *}$ & & & & & & & & & \\
\hline 6. Victim Blame & -.01 & $-.20 * *$ & $-.16^{* *}$ & -.03 & $.26 * *$ & & & & & & & & \\
\hline 7. Perpetrator Blame & $.12 * *$ & $.17 * *$ & $.13^{* *}$ & .03 & $-.27 * *$ & $-.58 * *$ & & & & & & & \\
\hline 8. Victim Wanted Sex & $-.09 *$ & $-.16^{* *}$ & $-.18 * *$ & -.05 & $.23 * *$ & $.64 * *$ & $-.59 * *$ & & & & & & \\
\hline 9. Victim “Led Perpetrator On” & -.04 & $-.17 * *$ & $-.16^{* *}$ & .02 & $.25 * *$ & $.68 * *$ & $-.54 * *$ & $.77 * *$ & & & & & \\
\hline 10. Victim Suffering & .06 & $.17^{* *}$ & $.08^{*}$ & .05 & $-.17 * *$ & $-.58 * *$ & $.49 * *$ & $-.49 * *$ & $-.50 * *$ & & & & \\
\hline 11. Perceived Promiscuity & -.07 & $-.17 * *$ & $-.11 *$ & .03 & $.28 * *$ & $.53 * *$ & $-.45 * *$ & $.55 * *$ & $.54^{* *}$ & $-.39 * *$ & & & \\
\hline 12. ARBS & .03 & -.01 & $.41^{* *}$ & $.08^{*}$ & $-.07 *$ & $-.41 * *$ & $.24 * *$ & $-.38 * *$ & $-.36 * *$ & $.22 * *$ & $.29 * *$ & & \\
\hline 13. BIAS & .001 & $.08^{*}$ & $.35 * *$ & .03 & $-.22 * *$ & $-.55 * *$ & $.34 * *$ & $-.47 * *$ & $-.47^{* *}$ & $.33 * *$ & $-.39 * *$ & $.76^{* *}$ & \\
\hline 14. MHS & -.01 & $.11 *$ & - & .05 & -.06 & $-.42 * *$ & $.21^{* *}$ & $-.24 * *$ & $-.30 * *$ & $.30 * *$ & $-.28 * *$ & $.70^{* *}$ & $.73^{* *}$ \\
\hline Range & $18-78$ & - & - & - & - & $1-7$ & $1-7$ & $1-7$ & $1-7$ & $1-7$ & $1-5$ & $1-5$ & $1-5$ \\
\hline Mean & 28.6 & - & - & - & - & 2.17 & 6.41 & 1.65 & 2.11 & 5.54 & 4.03 & 3.83 & 3.26 \\
\hline Standard Deviation & 12.9 & - & - & - & - & 1.13 & .82 & 1.11 & 1.20 & 1.50 & 1.11 & .66 & .68 \\
\hline
\end{tabular}

Participant gender ( 0 = cisgender men, 1 = cisgender women); participant sexual orientation ( 0 = heterosexual, $1=$ lesbian/gay), participant SA (sexual assault) perpetrator $(0=$ no, $1=$ yes $)$, participant $S A$ victim $(0=$ no sexual assault, $1=$ sexual assault $)$. ARBS = Attitudes Regarding Bisexuality Scale; BIAS = Bisexualities: the Indiana Attitudes Scale; MHS = Modern Homonegativity Scale. MHS was only administered to heterosexual participants and thus there is no correlation between sexual orientation and MHS score. ${ }^{*} p<.05 ; * * p<.001$. 
Table 3

Analyses of Covariance Examining Experimental Effects: F parameters

\begin{tabular}{|c|c|c|c|c|c|c|c|}
\hline Model Number & Predictor & $\begin{array}{l}\text { Victim } \\
\text { Blame }\end{array}$ & $\begin{array}{l}\text { Perpetrator } \\
\text { Blame }\end{array}$ & $\begin{array}{c}\text { Victim } \\
\text { Wanted } \\
\text { Sex } \\
\end{array}$ & $\begin{array}{l}\text { Victim “Led } \\
\text { Perpetrator } \\
\text { On” } \\
\end{array}$ & $\begin{array}{c}\text { Victim } \\
\text { Suffering }\end{array}$ & $\begin{array}{l}\text { Perceived } \\
\text { Promiscuity }\end{array}$ \\
\hline \multirow{6}{*}{$\begin{array}{l}\text { Model } 1 \\
\text { Participant } \\
\text { Characteristics }\end{array}$} & & & & & & & \\
\hline & Age & .01 & $11.86^{*}$ & $5.35 *$ & 1.03 & 2.55 & 3.17 \\
\hline & Gender & $18.35^{* *}$ & $8.32 *$ & $8.52 *$ & $13.46^{* *}$ & $14.32 * *$ & $12.49 * *$ \\
\hline & Sexual Orientation & $28.55^{* *}$ & $17.75^{* *}$ & $31.11 * *$ & $28.92 * *$ & $6.45^{*}$ & $14.96^{* *}$ \\
\hline & Sexual Assault Victim & 1.81 & 2.98 & $3.75^{*}$ & .06 & 2.16 & .004 \\
\hline & Sexual Assault Perpetrator & $52.56^{* *}$ & $62.29 * *$ & $47.73 * *$ & $46.21^{* *}$ & $20.96 * *$ & $59.41 * *$ \\
\hline \multirow{2}{*}{$\begin{array}{l}\text { Condition } \\
\text { Characteristics }\end{array}$} & Victim Sexual Orientation & 2.41 & .63 & $4.44^{*}$ & $4.30 *$ & 2.11 & $11.02 * *$ \\
\hline & Coercion Type & $15.28 * *$ & $11.24 * *$ & $4.26 *$ & $6.10^{*}$ & $11.21^{* *}$ & 2.24 \\
\hline \multirow{6}{*}{$\begin{array}{l}\text { Model } 2 \\
\text { Participant } \\
\text { Characteristics }\end{array}$} & & & & & & & \\
\hline & Age & .02 & $12.01 *$ & $5.38 *$ & 1.05 & 2.64 & 3.17 \\
\hline & Gender & $18.92 * *$ & $8.08^{*}$ & $8.26^{*}$ & $13.30 * *$ & $14.28 * *$ & $12.26^{* *}$ \\
\hline & Sexual Orientation & $28.53^{* *}$ & $17.62^{* *}$ & $30.98 * *$ & $28.82 * *$ & $6.53^{*}$ & $14.75^{* *}$ \\
\hline & Sexual Assault Victim & 2.04 & 3.09 & $4.20 *$ & .04 & 1.89 & .001 \\
\hline & Sexual Assault Perpetrator & $51.70 * *$ & $62.88 * *$ & $47.80 * *$ & $45.90^{* *}$ & $21.10 * *$ & $59.44 * *$ \\
\hline \multirow{3}{*}{$\begin{array}{l}\text { Condition } \\
\text { Characteristics }\end{array}$} & Victim Sexual Orientation & 2.39 & .63 & $4.41^{*}$ & $4.25^{*}$ & 2.08 & $11.06^{* *}$ \\
\hline & Coercion Type & $15.09 * *$ & $11.26^{* *}$ & $4.18^{*}$ & $6.10^{*}$ & $11.51^{* *}$ & 2.16 \\
\hline & Interaction & .35 & .27 & .52 & .09 & .90 & .25 \\
\hline
\end{tabular}

$* p<.05 ; * * p<.001$. 
Table 4

Marginal Means from Analyses of Covariance

\begin{tabular}{|c|c|c|c|c|c|c|c|}
\hline & & $\begin{array}{l}\text { Victim } \\
\text { Blame }\end{array}$ & $\begin{array}{l}\text { Perpetrator } \\
\text { Blame }\end{array}$ & $\begin{array}{l}\text { Victim } \\
\text { Wanted } \\
\text { Sex }\end{array}$ & $\begin{array}{l}\text { Victim } \\
\text { "Led } \\
\text { Perpetrator } \\
\text { On” } \\
\end{array}$ & $\begin{array}{l}\text { Victim } \\
\text { Suffering }\end{array}$ & $\begin{array}{l}\text { Perceived } \\
\text { Promiscuity }\end{array}$ \\
\hline \multirow{12}{*}{$\begin{array}{l}\text { Participant } \\
\text { Characteristics }\end{array}$} & Gender & & & & & & \\
\hline & Cisgender Men & 2.48 & 6.21 & 1.90 & 2.40 & 5.19 & 2.18 \\
\hline & Cisgender Women & 2.15 & 6.37 & 1.68 & 2.10 & 5.59 & 1.91 \\
\hline & Sexual Orientation & & & & & & \\
\hline & Heterosexual & 2.52 & 6.17 & 2.00 & 2.47 & 5.26 & 2.19 \\
\hline & Lesbian/Gay & 2.12 & 6.40 & 1.58 & 2.03 & 5.52 & 1.90 \\
\hline & Sexual Assault Victim & & & & & & \\
\hline & No & 2.37 & 6.24 & 1.87 & 2.24 & 5.31 & 2.04 \\
\hline & Yes & 2.26 & 6.34 & 1.71 & 2.26 & 5.47 & 2.05 \\
\hline & Sexual Assault Perpetrator & & & & & & \\
\hline & No & 1.99 & 6.55 & 1.47 & 1.91 & 5.68 & 1.69 \\
\hline & Yes & 2.65 & 6.02 & 2.11 & 2.59 & 5.10 & 2.40 \\
\hline \multirow{7}{*}{$\begin{array}{l}\text { Condition } \\
\text { Characteristics }\end{array}$} & Coercion Type & & & & & & \\
\hline & Physical & $2.07^{\mathrm{a}}$ & $6.38^{\mathrm{a}}$ & $1.66^{\mathrm{a}}$ & $2.08^{\mathrm{a}}$ & $5.61^{\mathrm{a}}$ & 1.95 \\
\hline & Verbal & $2.32^{\mathrm{b}}$ & $6.37^{\mathrm{a}}$ & $1.80^{\mathrm{a}, \mathrm{b}}$ & $2.26^{\mathrm{a}, \mathrm{b}}$ & $5.49^{\mathrm{a}}$ & 2.05 \\
\hline & $\begin{array}{l}\text { Alcohol Incapacitation } \\
\text { Victim Sexual Orientation }\end{array}$ & $2.57^{c}$ & $6.11^{\mathrm{b}}$ & $1.91^{\mathrm{b}}$ & $2.42^{\mathrm{b}}$ & $5.06^{\mathrm{b}}$ & 2.14 \\
\hline & Heterosexual & 2.42 & 6.25 & $1.88^{\mathrm{a}}$ & $2.34^{\mathrm{a}}$ & 5.33 & $2.00^{\mathrm{a}}$ \\
\hline & Lesbian & 2,22 & 6.31 & $1.64^{\mathrm{b}}$ & $2.09^{\mathrm{b}}$ & 5.53 & $1.86^{\mathrm{a}}$ \\
\hline & Bisexual & 2,31 & 6.30 & $1.85^{\mathrm{a}}$ & $2.32^{\mathrm{a}}$ & 5.30 & $2.27^{\mathrm{b}}$ \\
\hline
\end{tabular}

Given non-significant interactions, marginal means are calculated based on model one results, holding age at its mean. Followup least significant difference tests were only calculated when the omnibus F test was significant. Superscript letters are used to denote the results of these follow-up analyses when there are more than two categories of predictors. 
Table 5

Indirect Effects Models

\begin{tabular}{lccc}
\hline Indirect Effect Model Paths & $b$ & $s e$ & $p$ \\
\hline Lesbian $\rightarrow$ Perceived Promiscuity & -.41 & .09 & $<.001$ \\
Heterosexual $\rightarrow$ Perceived Promiscuity & -.27 & .09 & .002 \\
Perceived Promiscuity $\rightarrow$ Victim Blame & .47 & .03 & $<.001$ \\
Perceived Promiscuity $\rightarrow$ Perpetrator Blame & -.28 & .02 & $<.001$ \\
Perceived Promiscuity $\rightarrow$ Victim Wanted Sex & .49 & .04 & $<.001$ \\
Perceived Promiscuity $\rightarrow$ Victim “Led Perpetrator On” & .52 & .03 & $<.001$ \\
Perceived Promiscuity $\rightarrow$ Victim Suffering & -.46 & .05 & $<.001$ \\
\hline & & & \\
Indirect Effects Coefficient & estimate & $s e$ & $95 \% C I$ \\
\hline Lesbian $\rightarrow$ Perceived Promiscuity $\rightarrow$ Victim Blame & -.19 & .04 & $-.29,-.11$ \\
Heterosexual $\rightarrow$ Perceived Promiscuity $\rightarrow$ Victim Blame & -.13 & .04 & $-.22,-.04$ \\
Lesbian $\rightarrow$ Perceived Promiscuity $\rightarrow$ Perpetrator Blame & .12 & .03 & $.06, .18$ \\
Heterosexual $\rightarrow$ Perceived Promiscuity $\rightarrow$ Perpetrator Blame & .08 & .03 & $.02, .13$ \\
Lesbian $\rightarrow$ Perceived Promiscuity $\rightarrow$ Victim Wanted Sex & -.21 & .05 & $-.31,-.11$ \\
Heterosexual $\rightarrow$ Perceived Promiscuity $\rightarrow$ Victim Wanted Sex & -.13 & .05 & $-.23,-.04$ \\
Lesbian $\rightarrow$ Perceived Promiscuity $\rightarrow$ Victim “Led Perpetrator On” & -.22 & .05 & $-.33,-.12$ \\
Heterosexual $\rightarrow$ Perceived Promiscuity $\rightarrow$ Victim “Led Perpetrator On” & -.14 & .05 & $-.24,-.04$ \\
Lesbian $\rightarrow$ Perceived Promiscuity $\rightarrow$ Victim Suffering & .19 & .05 & $.10, .29$ \\
Heterosexual $\rightarrow$ Perceived Promiscuity $\rightarrow$ Victim Suffering & .12 & .05 & $.04, .22$ \\
\hline Indiect
\end{tabular}

Heterosexual $\rightarrow$ Perceived Promiscuity $\rightarrow$ Victim Suffering

Indirect effects calculated controlling for participant age, gender, sexual orientation, and sexual assault victimization an perpetration history as well as condition coercion type and the direct effect of victim sexual orientation on the outcome. 
Table 6

Sexual Orientation Subsample Regressions (standardized regression coefficients)

\begin{tabular}{|c|c|c|c|c|c|c|c|}
\hline $\begin{array}{l}\text { Condition Sexual } \\
\text { Orientation of Subsample }\end{array}$ & Predictor & $\begin{array}{l}\text { Victim } \\
\text { Blame }\end{array}$ & $\begin{array}{l}\text { Perpetrator } \\
\text { Blame }\end{array}$ & $\begin{array}{c}\text { Victim } \\
\text { Wanted Sex }\end{array}$ & $\begin{array}{c}\text { Victim “Led } \\
\text { Perpetrator On" }\end{array}$ & $\begin{array}{c}\text { Victim } \\
\text { Suffering }\end{array}$ & $\begin{array}{c}\text { Perceived } \\
\text { Promiscuity }\end{array}$ \\
\hline Bisexual & ARBS & $-.47 * *$ & $.25 *$ & $-.44 * *$ & $-.38 * *$ & $.24^{* *}$ & $-.34 * *$ \\
\hline & BIAS & $-.61 * *$ & $.33 * *$ & $-.53 * *$ & $-.46 * *$ & $.34 * *$ & $-.43 * *$ \\
\hline Lesbian & MHS & $-.35 * *$ & $.17 *$ & $-.23 *$ & $-.38 * *$ & $.28 * *$ & $-.34 * *$ \\
\hline
\end{tabular}

Calculated controlling for participant age, gender, sexual orientation, and sexual assault victimization and perpetration history as well as condition coercion type. Higher scores on the ARBS, BIAS, and MHS indicate more positive attitudes toward bisexual and lesbian women. * $p<.05 ; * * p<.001$. 